\title{
Convenções e ordem da natureza: algumas perspectivas históricas ${ }^{1}$
}

Conventions and the Order of Nature: some historical perspectives

Helge KRAGH²

\section{Resumo}

O texto apresenta alguns importantes exemplos históricos para ilustrar e discutir a natureza das convenções que têm sido adotadas no âmbito científico. Esclarece os argumentos usados por filósofos da chamada abordagem convencionalista para defender que teorias científicas nunca poderão ser representações absolutamente verdadeiras ou falsas sobre a natureza. Detalhes históricos e implicações para o ensino de ciências são discutidos ao longo do texto.

Palavras-chave: convencionalismo; história da ciência; epistemologia.

\section{Abstract}

The text presents some important historical examples to illustrate and discuss the nature of the conventions that have been adopted in the scientific realm. Clarifies the arguments used by philosophers of the call conventionalist approach to argue that scientific theories can never be absolutely true or false representations about nature. Historical details and implications for science education are discussed in the text.

Keywords: conventionalism; history of science; epistemology.

\footnotetext{
${ }^{1}$ Artigo traduzido por Jesus Cardoso Brabo do original em inglês: Kragh, Helge (2011). Conventions and the Order of Nature: some historical perspectives. RePoSS: Research Publications on Science Studies 15. Aarhus: Centre for Science Studies, University of Aarhus. <http://www.css.au.dk/reposs> Acessado em 18Set de 2015.

${ }^{2}$ Niels Bohr Archive, Niels Bohr Institute, Blegdamsvej 17, 2100 Copenhagen, Denmark.
} 


\section{Introdução}

Segundo a clássica filosofia da ciência convencionalista, teorias científicas não são e nunca poderão ser representações da natureza verdadeiras ou falsas. Historicamente associada aos cientistas franceses do início do século XX Pierre Duhem e Henri Poincaré, o convencionalismo sustenta que as leis e teorias, longe de serem apenas inferências com base na experiência, são definições e convenções escolhidas pelos cientistas São apenas as mais simples e econômicas maneiras de explicar certos fenômenos naturais ou classes de fenômenos (Newton, 1997, p.11-22).

Não é necessário aderir a qualquer convencionalismo ou alguma forma de construtivismo para reconhecer que a ciência envolve fundamentalmente conceitos e estruturas que não são dadas pela própria natureza, mas sim construções humanas. Como tal, eles poderiam ser diferentes do que são, porque são essencialmente escolhidos pelos cientistas por razões pragmáticas. Algumas vezes recomenda-se não colocar rótulos em fenômenos naturais, uma vez que esses rótulos são conceitos inventados por nós não fazem verdadeiramente parte da própria natureza, mas tais rótulos linguisticamente formulados, em forma de classificações e convenções, não apenas são inevitáveis, como também são epistemologicamente eficazes e de grande importância para a ciência real. Eles nos dizem algo sobre a natureza.

A proposta deste ensaio não é contribuir para a extensa literatura existente sobre o convencionalismo na ciência (Ben-Menahem 2006), mas apenas discutir de maneira exemplar e não muito sistemática o papel que as prescrições do tipo convencionalista podem desempenhar na Ciência. Os exemplos que uso são retirados da história das ciências físicas, química e astronomia. Eles são, em parte, voltados para aspectos educacionais, em particular em relação a aspectos da "natureza da ciência" ( $\mathrm{NdC}$ ) no ensino de ciências (Comas 1998; Flick \& Lederman 2006). Resumidamente, defendo que as discussões sobre $\mathrm{NdC}$ devem necessariamente incluir aspectos da visão convencionalista da ciência e mostrar de forma clara a diferença entre afirmações convencionalista e não-convencionalistas.

\section{O que é um elemento químico?}

Embora a fórmula $\mathrm{H}_{2} \mathrm{O}$ para água tenha sido um símbolo escolhido convencionalmente, não é completamente convencional. A fórmula esta relacionada ao fato empírico de que quando a água é decomposto é (térmica ou eletroliticamente) o resultado será sempre moléculas de hidrogênio $\left(\mathrm{H}_{2}\right)$ oxigênio $\left(\mathrm{O}_{2}\right)$, numa proporção de peso de 1:8 ou na proporção em volume de 2:1. A fórmula $\mathrm{H}_{2} \mathrm{O}$ é um símbolo iconográfico para este conhecimento que é experimentalmente independente de qualquer convenção (exceto a convenção trivial que as palavras "água", "hidrogênio" e "oxigênio" têm em seus significados usuais). Por outro lado, considerar seguinte afirmação:

A frequência ( $f$ ) e o período ( $T$ ) de um sistema oscilando harmonicamente são inversamente proporcionais, isto é, $f=1 / T$.

Esta é, obviamente, uma declaração desprovida de informação empírica, uma vez que só é semanticamente verdadeira por causa das definições dos termos. Embora nenhum experimento jamais possa refutar essa afirmação, alguns experimentos poderiam refutar a fórmula da água. A informação contida nesta fórmula não depende de qualquer forma não- 
trivial do significado dos termos "água", "hidrogênio" e "oxigênio". Assim, os químicos consideram um fato da natureza que a água é $\mathrm{H}_{2} \mathrm{O}^{3}$. Da mesma forma, é fato que o elemento químico hidrogênio tem número atômico $Z=1$ no sistema periódico, e que o oxigênio possui $Z=8$. No entanto, este não foi sempre o caso e tem status fatual só porque nós escolhemos um determinado parâmetro, o número atômico, como a propriedade de definição de um elemento. O sistema de classificação periódica de Mendeleev de 1869 foi, como outros sistemas do período inicial, baseado na relação existente entre elementos e suas massas atômicas. A massa atômica era a propriedade mensurável que definia elemento químico.

Avanços nos anos entre 1911 e 1914 como a descoberta da existência de isótopos, modelo atômico nuclear de Bohr-Rutherford e o advento do método de Moseley de determinação da carga nuclear por meio de espectroscopia de raios- $\boldsymbol{X}$, possibilitou a proposta de uma nova definição do que "realmente" seria um elemento químico. A nova proposta, que a chamada carga nuclear (ou número atômico) deve ser a propriedade definidora, inicialmente foi cerca de controvérsias, sendo adotada somente depois de muitos anos de discussão: Em 1921, a Comissão Alemã de Pesos Atômicos (Deutsche Atomgewichtkommission) decidiu adotar o número atômico como base para seu sistema periódico. Dois anos depois a mesma convenção foi adotada pela Comissão Internacional de Elementos Químicos (Paneth 1962; Kragh 2000; Holden, 2004)

A substituição da massa atômica $A$ pelo número atômico $Z$ foi claramente uma decisão baseada em uma escolha convencional. A Natureza não nos diz o que é um elemento, nós mesmos temos que decidir. As discussões na comunidade química poderiam ter tomado um rumo diferente. Os químicos poderiam concebivelmente ter concordado em manter a antiga definição com base na massa atômica, ou poderiam ter escolhido uma terceira alternativa. Embora não tenham sido forçados a mudar para o número atômico, haviam boas razões tanto racional quanto pragmática para fazer isso. A nova definição ainda hoje é aceita, mas isso só atesta sua robustez e não que ela seja mais "verdadeira" do que a antiga.

Mesmo reconhecendo que o sistema periódico deve ser baseado em um número ordinal diferente da massa atômica, havia outras possibilidades ao número atômico padrão associado ao núcleo atômico. Em algumas versões do sistema periódico de 1913-1916 é possível ver número ordinal 10, ao invés de 8, para o oxigênio. Alguns físicos e químicos acreditavam que existiam dois elementos desconhecidos entre o Hidrogênio e o Hélio, que implicava dois números ordinais a mais para o Hélio e os elementos seguintes. Com o reconhecimento do modelo de Bohr-Rutherford a ideia de átomos desse tipo foi abandonada, e hoje são considerados apenas como curiosos erros.

\footnotetext{
3 É claro, a partir de um ponto de vista filosófico assuntos são mais complicados (eles sempre são). Os filósofos têm debatido longamente sobre a composição da água, e poucos aceitam que a fórmula $\mathrm{H}_{2} \mathrm{O}$ seja um simples "fato da natureza." Veja, por exemplo, Van Brakel (2000).
} 


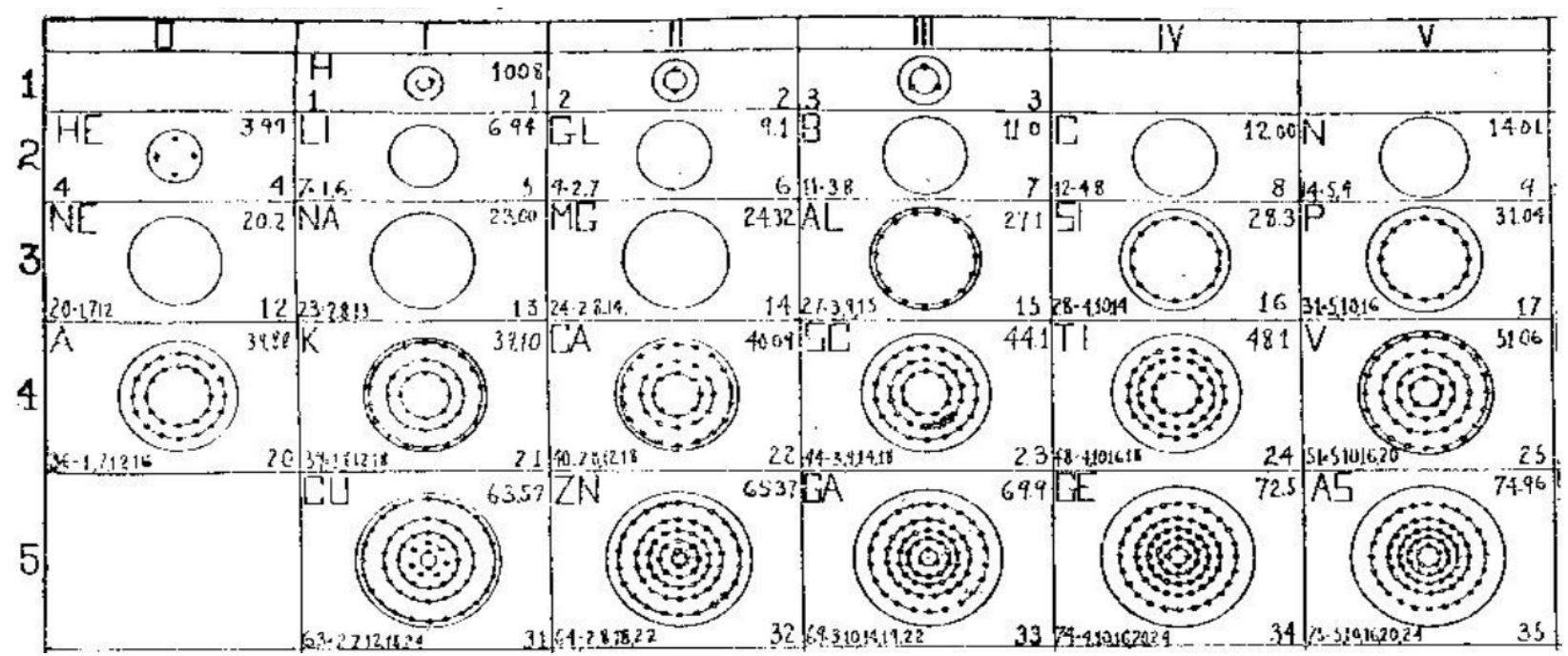

Parte de um sistema periódico e configurações eletrônicas dos elementos inventados pelo físico americano Albert Crehore em 1915. Observe os dois elementos não identificados com números ordinais 2 e 3 entre Hidrogênio e Hélio. Fonte: Crehore, A. (1915) The gyroscopic theory of atoms and molecules. Philosophical Magazine, 29, 310-322.

Mesmo com a redefinição de elemento químico, no início de 1920, a massa atômica não se tornou irrelevante. Desde que John Dalton introduziu o conceito de massa [peso] atômica mais de 200 anos atrás, têm-se discutido que unidades em massa de um elemento (ou um componente isotópico) deve ser usada - ver Holden (2004) e De Bièvre e Peiser (1992) para comentários históricos. Embora a grande maioria dos químicos no século XIX tenham seguido Dalton, usando a escala $H=1$, no final do século Wilhelm Ostwald, Bohuslav Brauner e outros propuseram escala $\mathrm{O}=16$ como alternativa, que, depois de algum tempo de disputa, passou a ser adotada. O posterior reconhecimento de que 0 oxigênio que ocorre naturalmente é uma mistura de três isótopos $\left({ }^{17} \mathrm{O}\right.$ e ${ }^{18} \mathrm{O}$ além do dominante ${ }^{16} \mathrm{O}$ ), na década de 1930 , levou a uma situação desconfortável os químicos que utilizavam o padrão $\mathrm{O}=16$, enquanto alguns físicos preferiram mudar o padrão para ${ }^{16} \mathrm{O}=$ 16. A última grande revisão veio em 1961, quando a Assembleia Geral da IUPAC, a União Internacional de Química Pura e Aplicada, decidiu adotar a unidade ${ }^{12} \mathrm{C}=12$, que ainda é a escala oficial entre químicos e físicos.

Mudanças nas unidades, como as que ocorreram no caso de massas atômicas são comuns e na maioria dos casos não tão dramáticas. Possuem um caráter puramente convencional e em grande parte são efetuadas por razões práticas, administrativas ou técnicas. As mudanças históricas do padrão $\mathrm{H}=1$ para o padrão ${ }^{12} \mathrm{C}=12$ não nos dizem nada sobre a natureza das coisas, mas nos dizem algo sobre a natureza e desenvolvimento da Ciência.

É importante ressaltar que as convenções, pertença ou não à ciência, são de natureza consensual e por isso incluem um forte elemento social. Convenções tem um significado prático se forem aceitas por uma grande parte da comunidade, não necessariamente de maneira imediata por toda a comunidade. Em longo prazo, é intolerável ou pelo menos altamente impraticável que uma convenção tenha sido aceita apenas por uma pequena parte da comunidade científica, enquanto outras partes dessa mesma comunidade adotam outras convenções. Convenções importantes têm de ser acordadas nas organizações 
científicas internacionais, para então serem usadas em livros didáticos, manuais e artigos de pesquisa.

Pode ser difícil alcançar o consenso desejado nos casos em que convenções transcendem uma única disciplina científica ou levem com elas marcas nacionais ou políticas ou outro significado externo. Isso é exemplificado pelo caso da redefinição de certos elementos químicos, que enfrentou oposição por estas razões. Muitos químicos consideravam intolerável que o conceito de elemento, o próprio fundamento das ciências químicas, deveria ser baseado em um parâmetro físico que podia ser medido apenas por métodos físicos (Kragh, 2000). A rivalidade profissional entre químicos e físicos foi uma das principais razões, e a rivalidade nacional outra razão menor, para que a nova definição fosse adotada oficialmente apenas uma década após ter sido proposta.

\section{Declarações empíricas e convencionais}

Como vimos, algumas afirmações sobre a natureza são de caráter convencional. Essencialmente decisões tomadas pelos cientistas e suas organizações profissionais. Outras declarações têm um caráter empírico, no sentido de que elas são verdadeiras ou são falsas, devido a natureza ser como é. Enquanto o último tipo de declaração pode ser testada por meio de experiências e observações, o primeiro tipo não pode. É de suma importância, não menos importante em contextos educativos, distinguir a diferença entre esses dois tipo de declaração e reconhecer os diferentes status epistemológicos que elas têm. Não é menos importante reconhecer que a distinção nem sempre é fácil e sem problemas. A seguir apresento uma coleção de exemplos um tanto quanto arbitrários:

1. Um dia equivale a 24 horas?

2. Todos os compostos químicos orgânicos são compostos de carbono?

3. Em mecânica clássica, a energia cinética é $\mathrm{E}_{\mathrm{C}}=1 / 2 \mathrm{mv}^{2}$ ?

4. As aranhas não são insetos?

5. Carbono-12 tem peso atômico 12.000 .000 ?

6. Plutão é um planeta?

7. Água consiste dos elementos hidrogênio e oxigênio?

8. A velocidade da luz no vácuo é $c=299792458 \mathrm{~m} / \mathrm{s}$ ?

9. O universo sempre existiu?

10. Força é igual ao produto da massa e aceleração $(F=m . a)$ ?

Todas as declarações, formuladas aqui como perguntas, dizem respeito a fenômenos, objetos ou processos naturais e, portanto, aparentemente, pertencem ao domínio da ciência. O que importa não é tanto que as declarações sejam verdadeiras ou não, mas sim razões pelas quais elas são verdadeiras ou falsas (ou talvez nenhum valor de verdade possa ser atribuído). Enquanto algumas perguntas podem ser respondidas de forma inequívoca e outras de maneira mais ambígua, não está claro se pertencem grupo de declarações convencionais ou empíricas.

As aranhas não são insetos (\#4) simplesmente porque eles não se encaixam em uma definição de inseto, que, entre outras características, exige que um inseto adulto possua dezesseis patas (e aranhas possuem oito). São criaturas assustadoras em muitos aspectos como insetos, mas contanto que mantenhamos a nossa definição, elas não poderão ser incluídas nessa classe de animais. Não faz sentido estudar aranhas a fim de descobrir se eles realmente são insetos ou não, tão pouco, faz sentido investir em experimentos precisos com o objetivo de descobrir se carbono-12 realmente tem massa atômica 12. Se verificarmos 
que a determinação da massa de alta precisão resultar em, digamos, uma massa atômica igual a 12,008 $\pm 0,001$, tudo o que podemos fazer é colocar a culpa na discrepância do experimento. Devemos descobrir uma aranha com oito patas, quando... Deus sabe o quê.

Como já foi referido, questões científicas, dependem de convenções que mudam ao longo da história, porque as convenções são negociáveis e podem ser renegociadas. A medida que os cientistas se tornam mais bem informados, terão necessidade de alterar suas convenções e definições, tal como ilustrado pelo caso das unidades dos elementos químicos. Voltarei a essa questão, mas primeiro quero oferecer alguns breves comentários sobre as perguntas \#3 e \#9. De acordo com um cientista newtoniano a energia cinética de um corpo em movimento é de fato $1 / 2 \mathrm{mv}^{2}$ ? Será que os físicos do passado decidiram que precisavam de uma quantidade de energia definida exatamente dessa forma? Ou será que eles mediram a energia cinética dos corpos com massa e velocidade variável para descobrir a relação?

A questão é historicamente complicada porque se refere a um período no qual o conceito geral de energia ainda não tinha sido estabelecido. Durante o século XVIII irrompeu uma grande controvérsia debatida entre filósofos naturais defensores do conceito leibniziano de vis viva $\left(m v^{2}\right)$ como representação da "força" de um corpo em movimento e os defensores do conceito cartesiano de "quantidade de movimento" (correspondente a mu). Para efeitos do presente caso, não vamos considerar os detalhes desse interessante debate (Smith, 2006), mas adotarei uma perspectiva moderna do nosso conhecimento da energia. Se quisermos associar energia a movimento, razões dimensionais implicam $\mathrm{mv}^{2} \mathrm{e}$ razões de simplicidade favorecem apenas esta quantidade. No entanto, a energia cinética não é $m v^{2}$, mas $1 / 2 m v^{2}$. De onde vem o fator $1 / 2$ ? A inclusão do fator pode ser justificada pela referência ao princípio geral de conservação da energia mecânica (cinética e potencial), que leva à expressão $E_{\text {kin }}=1 / 2 m v^{2}$.

Bem diferente é a declaração \#9. De acordo com a atual teoria padrão do Big Bang a idade do universo está próxima de 13,4 bilhões de anos, com uma incerteza de apenas 0,2 bilhões de anos. Assumindo que esta teoria está correta, aparentemente, segue-se que o universo nem sempre existiu, uma visão que em última análise é baseada em observações astronômicas, juntamente com a teoria física avançada. Teríamos, então, dizer que a declaração \#9 é empiricamente errada e não de natureza convencional ou semântica.

Mas não tão rápido! A semântica é de fato parte crucial da declaração. Pode-se argumentar que o significado do termo temporal "sempre" garanta que o universo sempre existiu e que, portanto, a declaração é semanticamente verdadeira, independentemente se houve ou não um Big Bang. Ou seja, dizer que o universo sempre existiu não quer dizer que ele tem existido em uma eternidade de tempo, mas que ele já existia desde que não havia tempo. A negação dela "o universo nem sempre existiu", convida-nos a considerar a ideia decididamente estranha de um tempo passado em que não havia universo e, portanto, absolutamente nada. De acordo com as concepções geralmente mantidas do termo "tempo" e "universo", esta é uma ideia impossível. Consequentemente, temos que concluir que o universo, embora não seja eterno, sempre existiu, mas que esta conclusão é baseada unicamente em razões conceituais e semânticas. É uma conclusão que não diz absolutamente nada sobre o universo físico e da forma como se desenvolveu através da história cósmica (ver também a última secção desse texto). Pode-se acrescentar que as considerações mencionadas pressupõe o sentido tradicional de "universo". Se houver muitos universos, por exemplo, um após o outro de forma cíclica ou apenas um universo anterior à atual, a resposta pode ser diferente. 


\section{O conceito de força}

A segunda lei de Newton da mecânica clássica supõe que uma força aplicada sobre um corpo produz uma aceleração inversamente proporcional à massa do corpo. A lei é tipicamente escrita como:

$$
F=m a=\frac{d p}{d t}
$$

onde pé o momentum mv. A segunda lei de Newton pode ser entendida de maneiras muito diferentes (Hanson 1965, p.99-105; Jammer 1962, p.200-240). Assim, pode ser pensada como uma fórmula que resume um grande corpo de experiência de fenômenos mecânicos. Também pode ser concebida como uma definição de uma quantidade útil chamada "força", ou ainda pode ser considerada como uma técnica de medição de força, aceleração ou massa. E há outras possibilidades.

A questão do status epistemológico da segunda lei do movimento está longe de ser nova, pois tem sido discutida desde tempos de Newton. Como a lei ocupa uma posição central nos livros didáticos introdutórios em física, o seu status não é apenas do interesse filosófico, mas também de óbvia importância didática. Livros didáticos de física, por vezes, introduzem a segunda lei de Newton como uma lei empírica, que poderia ser experimentalmente testada, enquanto outros livros salientam que trata-se de uma convenção ou definição e, portanto, imune a refutação. Para citar um livro-texto universitário amplamente utilizado, a segunda lei de Newton "é mais uma definição do que uma lei" (Alonso e Finn 1968, p. 459). Embora a mecânica newtoniana há muito tempo tenha sido substituída pela mecânica quântica e pela teoria da relatividade, a questão do status da segunda lei continua a atrair a atenção científica. Tentativas contemporâneas para testar a precisão da lei estão associadas com ideias para a formulação da chamada dinâmica newtoniana modificada (MOND) como uma explicação alternativa de observações da matéria escura (Hacyan 2009). Todavia, se a lei de Newton é apenas uma definição, não faz sentido testar a sua precisão.

O matemático, físico e filósofo francês Henri Poincaré adotou uma visão convencionalista de matemática, bem como da física. Segundo ele, os princípios gerais da ciência não são nada mais que descrições econômicas de fatos observados; criações livres da mente humana e, como tal, não dizem nada sobre fatos. Em particular, eles não explicam tais fatos. Por exemplo, no final do século XIX, a questão do espaço curvo, ou seja, se o espaço físico poderia seguir uma geometria diferente da de Euclides, começou a ser discutida entre alguns filósofos e astrônomos. Poincaré argumentava que era inútil investigar, por meio de observações astronômicas se o espaço era realmente Euclidiano ou não. O que importava, disse ele, que dessa forma a geometria espaço poderia ser descrita da forma mais simples e econômica, e não havia nenhuma razão para abandonar o tradicional espaço plano.

Em relação às leis da mecânica newtoniana, a atitude de Poincaré era essencialmente a mesma. Para ele, a força de Newton poderia ser medida apenas pela aceleração que impressiona um corpo de massa conhecida. Por esta razão, ele concebia a lei de definição de força e massa como um mero coeficiente introduzido por razões de cálculos. Em sua obra clássica Science and Hypothesis ele escreveu [Poincaré 1952, pp 104-105.]:

Os princípios da mecânica apareceu-nos pela primeira vez como verdades experimentais, mas fomos obrigados a usá-los como definições. É por definição que a força é igual ao produto da massa pela aceleração; um princípio que, doravante, foi além do alcance de qualquer experimento 
futuro. No entanto, não podemos dizer que esses princípios não verificáveis são absolutamente desprovidos de qualquer significado. Apesar de não poderem ser refutados pela experiência, podemos aprender com eles algo de útil para nós.

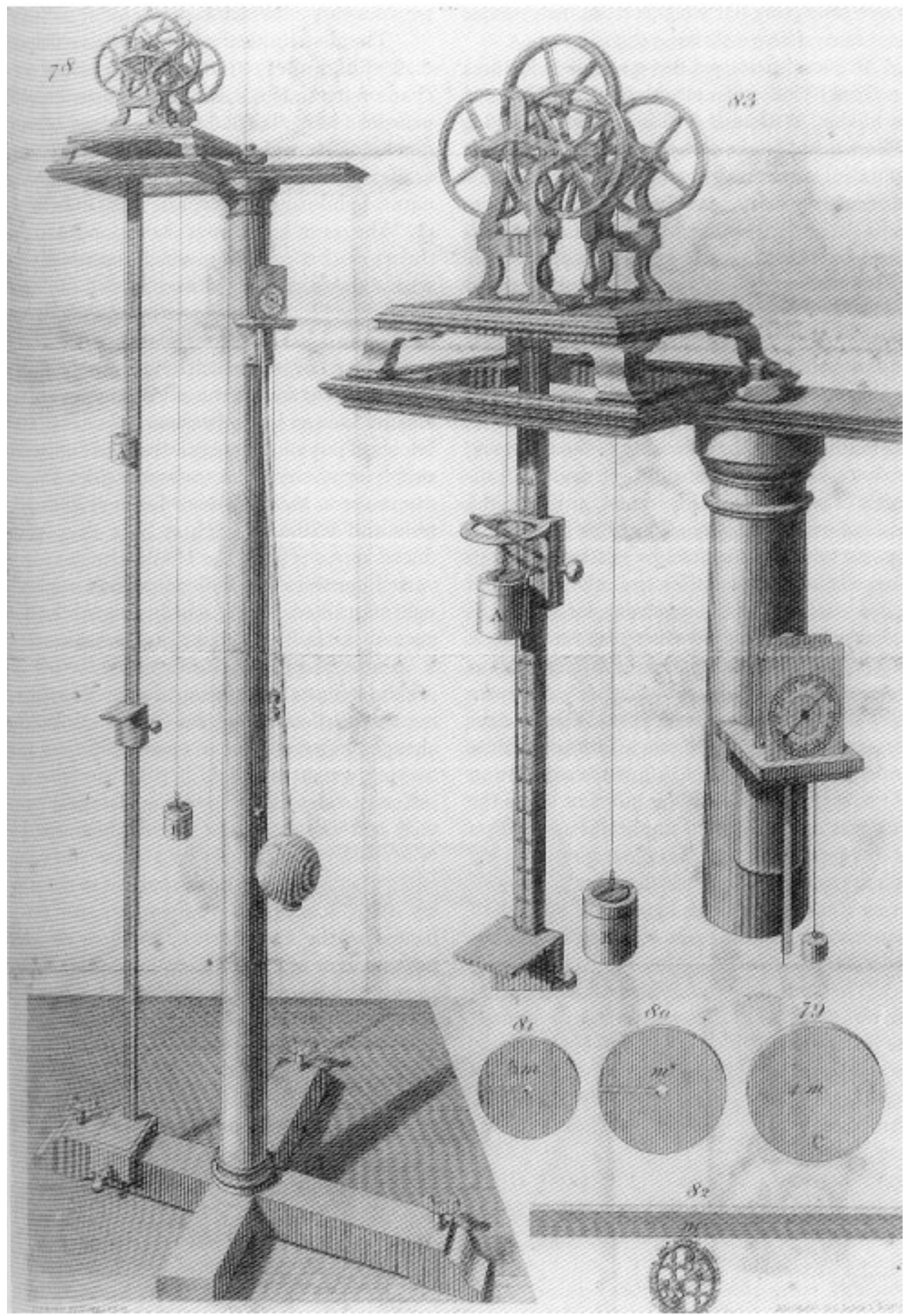

O aparelho concebido pelo matemático de Cambridge George Atwood, na década de 1770, foi projetado para demonstrar e verificar as leis do movimento de Newton sob forças constantes.

Enquanto alguns usaram muitas vezes a máquina de Atwood para testar a segunda lei de Newton, outros apenas assumiram a verdade da lei e consideram a máquina como uma mera ajuda heurística em entendê-la. Ilustração da descrição de Atwood de 1784. 
No entanto, Poincaré não considerou inúteis as leis de Newton e advertiu contra aqueles que "se perguntam se o sábio não é um joguete de suas próprias definições e se o mundo que pensa que descobre não é simplesmente criado por seu próprio capricho" (1952, p. XVIII).

Para Poincaré as leis da mecânica de Newton, são idealizações e não se segue do seu status convencional de que elas sejam de fato aproximadamente válidas no mundo real. Poincaré resumiu sua versão do convencionalismo da seguinte forma: "Assim se explica como a experiência pode servir de base para os princípios da mecânica, e ainda assim nunca invalidá-los." Como sabemos hoje, não só leis da mecânica de Newton podem ser invalidadas experimentalmente, como elas foram invalidadas dessa maneira. A este respeito Poincaré estava errado, embora sua filosofia convencionalista geral da ciência não é desmentida simplesmente por este motivo. Em qualquer caso, a mensagem importante é que, porque os conceitos e princípios convencionais fazem parte da estrutura da física teórica, não se segue que a física seja reduzida a um mero sistema de convenções.

\section{O que é um ácido?}

Desde a época da alquimia sabe-se que determinadas substâncias compartilham algumas propriedades comuns, tais como um gosto ácido e reatividade com calcário e muitos metais. O ácido sulfúrico e o ácido acético pertencem ao grupo dos ácidos, mas, além desse nível fenomênico, está longe de ser óbvio o que os dois líquidos têm em comum. Qual a causa das propriedades comuns?

Por volta de 1780, Lavoisier propôs que o oxigênio deve estar presente em todos os ácidos e é responsável por suas propriedades características (não é por acaso que a palavra oxy-gen, derivada do grego, significa "princípio ácido" ou "raiz de acidez"). A definição oferecida por Lavoisier teve curta duração e teve de ser abandonada quando descobriu-se que, por exemplo, ácidos como $\mathrm{HCl}, \mathrm{HCN}$ e $\mathrm{H}_{2} \mathrm{~S}$ não contêm oxigênio. Claro, poderia-se manter a definição, mas ao preço de negar o status de ácido a substâncias como o ácido clorídrico. Os químicos acharam que esse era um preço muito elevado, e, em 1838, Justus von Liebig, na Alemanha sugeriu uma nova definição: um ácido é uma substância que contém hidrogênio, em uma tal forma que ele pode ser substituído por um metal (por exemplo, $2 \mathrm{HCl}+\mathrm{Zn} \rightarrow \mathrm{ZnCl} 2+\mathrm{H} 2)$. Um século mais tarde, depois da aceitação da teoria eletrolítica de dissociação de Svante Arrhenius, um ácido foi entendido como uma substância que, em solução aquosa, pode liberar seu hidrogênio sob a forma de íons $\mathrm{H}^{+}$. Em concordância com essa definição, em 1909, o químico dinamarquês S.P.L. Sorensen introduziu a medição do pH para a acidez de uma solução, definido pH como = - $\log \left[\mathrm{H}^{+}\right]$, onde $\left[\mathrm{H}^{+}\right]$ou $\left[\mathrm{H}_{3} \mathrm{O}^{+}\right]$é concentração molar desses íons [Szabadvary, 1964].

Uma definição mais abrangente de ácidos foi proposta em 1923, de forma independente pelo dinamarquês Johannes N. Brønsted e pelo inglês Thomas M. Lowry, segundo a qual um ácido é um doador e uma base de um receptor de prótons (Kauffman 1988). Esta definição tem certas vantagens, em especial, que não pressupõem a água como solvente. Por outro lado, a definição torna-se problemática se tomada literalmente, pois implica que quase todos os compostos de hidrogênio tenham que ser classificados como ácidos. Isso o torna pouco útil para compreender as substâncias água, amônia e metano $\left(\mathrm{H}_{2} \mathrm{O}, \mathrm{NH}_{3}\right.$, e $\mathrm{CH}_{4}$, respectivamente) como ácidos. . Para tais substâncias, embora estes sejam muito pequenas, a força ácida (Ka) pode ser atribuída experimentalmente. Correspondentemente, valores de pKa, definidos como pK = - log [Ka], são muito grandes. 
Como se pode ver, a compreensão ou definição da natureza dos ácidos se assenta basicamente em razões pragmáticas. Quantidades tais como Ka e pKa são úteis, mas não refletem características essenciais do mundo molecular. O caso é o mesmo para o conceito de $\mathrm{pH}$, de modo que, obviamente, é apenas uma medida convencional e prática da acidez de um ácido. A equação $\mathrm{pH}=-\log \left[\mathrm{H}^{+}\right]$possui grande utilidade prática em experimentos, mas em si está além do alcance da experiência, porque o pH não pode ser medido independentemente de $\left[\mathrm{H}^{+}\right]$que é apenas uma convenção, embora certamente não seja uma convenção arbitrária. É uma medida eminentemente útil de acidez que faz com que seja possível reconhecer as relações químicas, que de outra forma permaneceriam ocultas. Em geral, as convenções estão associadas a potenciais epistêmicos e, neste contexto, uma determinada convenção pode ser reconhecida como sendo epistemologicamente mais apropriada do que outra convenção alternativa, embora seja nem mais nem menos verdadeira.

Nos primeiros anos do século XX não era comum distinguir nitidamente entre eletrólitos fracos e fortes. De acordo com a teoria de Arrhenius, acreditava-se que os eletrólitos fortes, tais como $\mathrm{NaCl}, \mathrm{HNO}_{3}$ e $\mathrm{HCl}$ fossem apenas parcialmente dissociados em solução aquosa, apenas com maior grau de dissociação de $\mathrm{H}_{2} \mathrm{~S}$ e outros eletrólitos fracos (Wolfenden 1972; Laidler 1993, p.209-216). Havendo N partículas de um eletrólito binário AB em uma solução, de acordo com a suposição básica de Arrhenius, os componentes iônicos dissociadas iriam entrar num estado de equilíbrio em conjunto com as moléculas que não haviam se dissociado, $A B \leftrightarrows A^{+}+B^{-}$. Significando que o grau de dissociação $\alpha$, expressaria o número total de partículas:

$$
\mathrm{N}(1-\alpha)+2 \mathrm{~N} \alpha=\mathrm{N}(1+\alpha) \text {, onde } 0 \leqq \alpha \leqq 1
$$

Por exemplo, em 1887, com base em medições das diminuições do ponto de congelamento e condutividade elétrica, Arrhenius concluiu que uma solução fortemente diluída de um mol de $\mathrm{HCl}$ daria origem a 1,93 mols de íons $\left(\mathrm{H}^{+}\right.$e $\left.\mathrm{Cl}^{-}\right)$ou invés de 2 mols. Da mesma forma, em suas primeiras experiências de pH, em 1910, Sørensen encontrou valor de $\mathrm{pH}=1,04$ para uma solução de $\mathrm{HCl}$ 0,100M. Os resultados de Arrhenius e Sørensen foram vistos como razoáveis para momento, daí foi aceito que $\alpha<1$ para todos os eletrólitos.

Hoje qualquer estudante de química reconhece que o valor de Sørensen não pode ser verdade, para o eletrólito $\mathrm{HCl}$ - por sua definição como um eletrólito forte completamente dissociado em uma solução aquosa diluída. Isto implica saber de antemão que, em uma solução 0,1 $\mathrm{M},\left[\mathrm{H}^{+}\right]=0,1 \mathrm{e}$, consequentemente, $\mathrm{pH}=1$. Não precisamos medir o pH para saber o resultado. Para um químico de 1915, a questão era empírica. Só poderia ser respondida pelo experimento. Em meados da década de 1920, foi reconhecido que os eletrólitos fortes eram, de fato, completamente dissociados - contrariamente à opinião de Arrhenius - que resultou na correspondente definição de eletrólitos fortes. Observe que a definição alterada do que se constitui como um ácido forte não era puramente convencional, mas sim necessária por causa dos resultados de medidas que provaram que eletrólitos fortes eram completamente ionizados. A definição de Arrhenius de eletrólitos fortes foi refutada pela experiência e nenhuma estratégia convencional pôde salvá-la. 


\section{A ascensão e queda de Plutão}

Em 1930, o astrônomo americano Clyde Tombaugh detectou um corpo celeste insignificante que ele identificou como um planeta trans-netuniano e denominou de Plutão. Muito pouco se sabia do novo planeta, exceto que ele era pequeno e muito distante. Acabou por ser entendido que, embora Plutão girasse periodicamente em torno do Sol, e, a este respeito se qualifica como um planeta, é um dos mais incomuns. Não só sua massa é

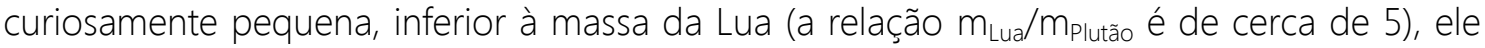
também se move em uma órbita altamente excêntrica com uma inclinação considerável em relação às órbitas dos outros planetas. Sua inclinação orbital é $17,15^{\circ}$ e sua excentricidade é de 0,25 , ambos os valores muito maiores do que os demais planetas. Como pode ser um pequeno e ao mesmo tempo respeitável planeta? Na década de 1990 os astrónomos encontraram uma série de objetos cometóides no chamado cinturão de Kuiper, que eram quase tão pesados quanto Plutão, movimentando-se em órbitas tão excêntricas e inclinadas quanto ele. De repente, o status de Plutão como um planeta tornou-se problemático: se Plutão for considerado um planeta, então temos considerar também como planetas os novos objetos recém descobertos? Os astrônomos não ficaram felizes com a perspectiva de ter que adicionar uma centena ou mais aos nove planetas já existentes.

A natureza não se preocupe se a aranha é um inseto ou não, se o metano é um ácido ou não, ou se Plutão é um planeta ou não. Ela graciosamente deixa tais preocupações para os cientistas, neste último caso, para os astrônomos. A questão surgiu em uma discussão durante a 26a Assembléia Geral da União Astronômica Internacional (IAU) durante sua reunião em Praga, em 2006, onde foi decidido, por maioria de votos, reclassificar Plutão como planeta anão [IAU; Weintraub 2007]. Entre as razões dessa decisão estava a que Plutão, durante sua jornada no espaço, cruza a órbita de Netuno, algo que é suposto que um planeta respeitável poderia fazer. Assim, por votação restaurou-se o número de planetas ao que eram considerados assim antes descoberta de Tombaugh. Não há dúvida que Tombaugh descobriu um novo objeto celeste, mas hoje seria correto dizer que ele descobriu um nono planeta? Se assim for, sua foi descoberta "redescoberta" pela Assembléia Geral da IAU em 2006?

Aliás, existem outros casos na história da astronomia nos quais o número de planetas mudou em virtude de releitura teórica. O mais famoso está relacionado com a revolução copernicana, quando o número de planetas foram reduzidos de sete para seis - apenas por se colocar o Sol e não a Terra no centro do universo. O número menor fez Rheticus, um dos poucos alunos de Copérnico, se alegrar tanto, que ele escreveu em seu trabalho Narratio Prima de 1541: "O que é mais agradável à obra de Deus do que o primeiro e mais perfeito mundo possa ser resumido no primeiro e mais perfeito número?" (Rosen 1959, p. 147).

À primeira vista, pode parecer estranho, até mesmo milagroso, que os astrônomos possuam o poder de transformar um planeta em um não-planeta. Claro, os astrônomos reunidos em Praga em 2006 não tinham qualquer poder sobre o universo, nem mesmo poderiam causar a menor mudança no curso de Plutão sobre o céu. Felizmente desconhecendo a sinistra decisão de Praga, Plutão continuou seu curso, como tem feito por incontáveis eras. Como foi o caso da redefinição dos elementos químicos, a nova definição de planetas foi feita por razões pragmáticas e de consistência. Caso os astrônomos um dia decidam restaurar o status de planeta para Plutão, eles são livres para fazê-lo. 


\section{A velocidade da luz}

O raio da Terra é de aproximadamente $6366 \mathrm{~km}$. Presumivelmente pode haver significativas variações de tamanho, mas a figura esférica, em um certo sentido, não foi escolhida de forma acidental. A circunferência da Terra $2 \pi R$ é uma quantidade medida geodesicamente, mas, dada nossa convenção histórica derivada da unidade de comprimento, tal medida não pode ser muito diferente do valor $\mathrm{R}=6366 \mathrm{~km}$. Esse valor foi o resultado da convenção métrica proposta pela Academia Francesa de Ciências em 1791 e aprovada pela Assembleia Nacional em Paris no mesmo ano. De acordo com esta convenção uma unidade de comprimento (um metro) deve ser um décimo milionésimo do meridiano da Terra ao longo de um quadrante sobre Paris [Alder, 2004]. Em outras palavras, foi definido que um meridiano completo possui o comprimento de $40.000 \mathrm{~km}$, a partir do qual se segue (assumindo uma Terra esférica) um raio de $r=40.000 / 2 \pi \mathrm{km}=$ $6366 \mathrm{~km}$.

A nova unidade de comprimento, mas tarde, foi transformada em uma barra métrica feita de platina e, desde 1889, feita de uma liga de iridio-platina. Este tipo padrão de material foi utilizado até 1960, quando a Conferência Geral de Pesos e Medidas (CGPM) redefiniu o metro como 1.650.763,73 comprimentos de onda de uma linha de emissão no espectro laranja do isótopo de Kriptônio Kr-86. Basta dizer que há boas razões técnicas para essa definição aparentemente estranha e definitivamente não-pedagógica. Ainda mais tarde, em 1983, a CGPM decidiu substituir a definição espectroscópica com o atual, que está diretamente baseado na velocidade da luz no vácuo:

O metro é o comprimento do trajeto percorrido pela luz no vácuo durante um intervalo de tempo de 1/299 792458 de um segundo.

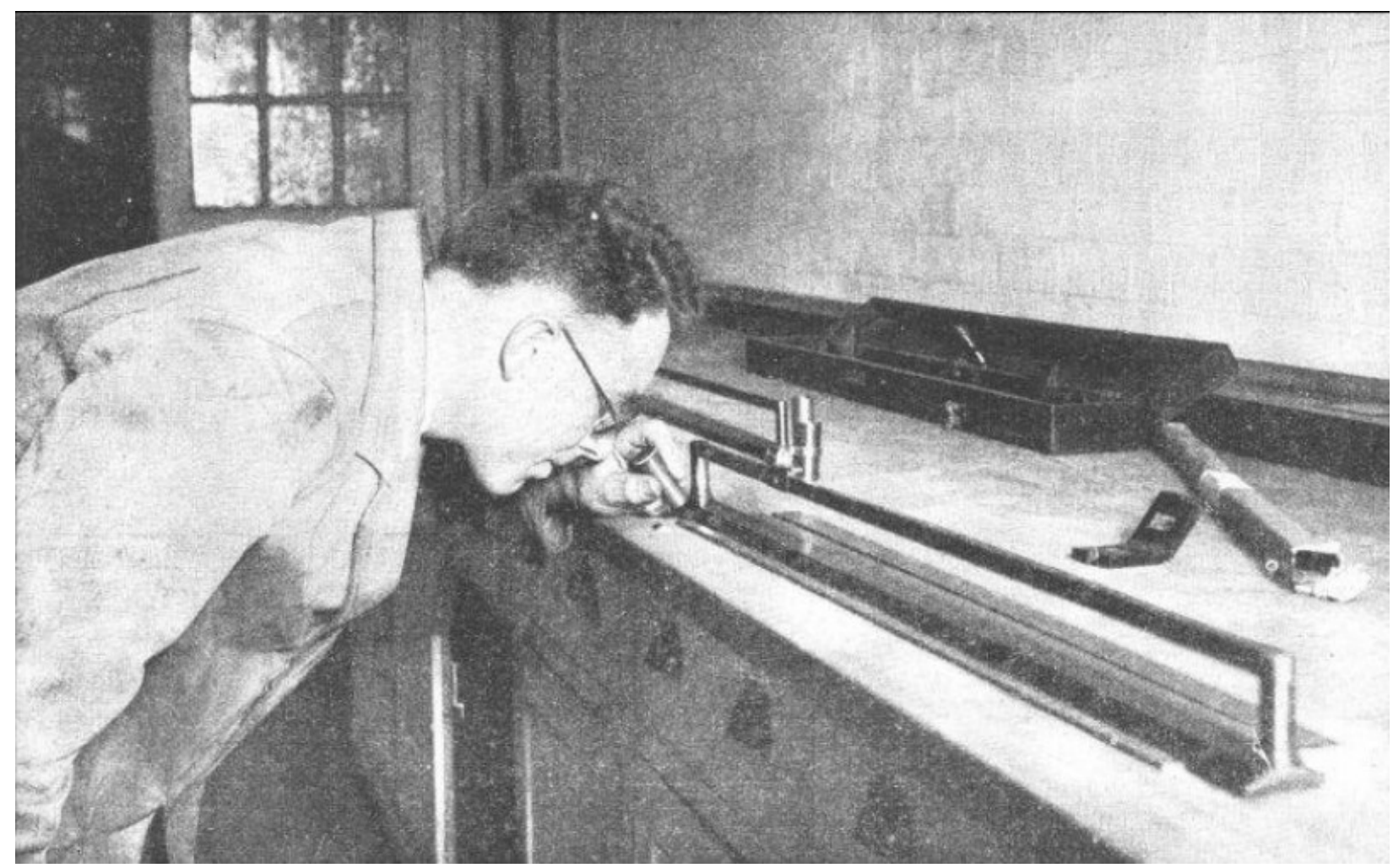

Medindo uma unidade de comprimento. Neste caso, não é a barra metro francesa, mas o equivalente ao padrão imperial da Jarda, estabelecido pelo Parlamento britânico em 1855. 
O número 299.792.458 é a velocidade da luz no vácuo, c, na unidade m/s. As várias redefinições do metro, de 1791 a 1983, foram feitas por razões técnicas (precisão, confiabilidade, reprodutibilidade, etc.) e, claro, com a devida consideração para uma continuidade entre as definições. Os metros antigos diferem do atual, mas na maioria dos casos a diferença é insignificante (Layer, 2008).

Não é por acaso que a velocidade da luz que entrou diretamente na definição do metro. c é reconhecida como sendo uma constante absolutamente fundamental da natureza. Embora isso nem tenha sido o caso. Quando Ole Rømer determinou a velocidade finita da luz, em 1676, era apenas mais um parâmetro físico, entre outros, em princípio, não tão diferente da velocidade do som. Mas, rapidamente se descobriu que a luz se propaga com a mesma velocidade em todo o universo. Como ficou claro com a descoberta de James Bradley das aberrações das estrelas fixas em 1728. Mais de um século depois, Maxwell percebeu que c poderia ser expressa por constantes de vácuo que aparecem na sua teoria eletromagnética. Finalmente, com a teoria especial da relatividade de Einstein, de 1905, a velocidade da luz elevou-se a uma constante verdadeiramente fundamental da natureza, uma quantidade que nem sequer depende do movimento da fonte de luz em relação ao detector.

De forma notável, o valor numérico de c deixa de ser determinado experimentalmente, e, por definição, passa a ser rigidamente:

$$
c \equiv 299792.458 \mathrm{~km} / \mathrm{s}
$$

Nem mais, nem menos. A natureza convencional da quantidade é sublinhada pela sua falta de incerteza. Embora os valores anteriores do $c$ terem sido estabelecidos experimentalmente $e$, portanto, lidando com uma incerteza experimental, isso não era mais o caso. Aqui estão algumas determinações anteriores da constante:

$$
\begin{aligned}
& 1882, c=299.860 \quad+/-30 \mathrm{~km} / \mathrm{s} \\
& 1932, c=299.774+\quad+/-10 \mathrm{~km} / \mathrm{s} \\
& 1958, c=299.792,5+\quad+/-0,4 \mathrm{~km} / \mathrm{s} \\
& 1967, c=299.792,56 \quad+/-0,11 \mathrm{~km} / \mathrm{s}
\end{aligned}
$$

Como esperado, a incerteza experimental diminuiu ao longo do tempo, mas claro, continuou a ser finita até 1983. A atual "incerteza" $\Delta c=0$ não é uma expressão de uma experiência soberbamente precisa, mas de uma convenção.

A razão pela qual os físicos podem decidir o valor numérico de c está relacionada ao fato dela expressar uma quantidade que é uma constante dimensional. Se fosse um número puro ou que variasse no espaço e no tempo, eles não teriam tido essa liberdade. Em princípio, não é mais de interesse, na verdade, nem mesmo significativa, medir a velocidade da luz. Não é mais significativa do que medir o comprimento da barra de metro padrão em 1900. Observe como algumas quantidades físicas podem mudam o seu status de empírico para convencional, ou de convencional para empírico. Enquanto o comprimento do metro padrão em Paris até 1960 foi fixado convencionalmente, recentemente se tornou uma grandeza empírica significativa que pode ser medida.

Considerando que o valor da velocidade da luz é fixado por definição, parece que possivelmente não possa variar no tempo. Isso não se deve ao fato de tratar-se de uma constante da natureza, mas por ter ser definida para um certo valor. No entanto, existem teorias cosmológicas modernas que operam com uma velocidade da luz variável (VSL) no passado cósmico (Kragh, 2006). Estas cosmologias do tipo VSL são controversas, por outras razões, devido à suposição básica problemática $c=c(t)$. Alguns críticos têm argumentado que desde c é apenas um fator de conversão convencional entre comprimento e tempo, 
portanto seria ilegítimo postular que tal fator varia no tempo (Ellis \& Uzan 2005). Como um crítico expressou a objeção (Duff 2004, p. 3):

É operacionalmente sem sentido e confuso falar sobre variação de tempo de constantes dependentes de unidades arbitrárias, cujo único papel é agir com fator de conversão. Por exemplo, além de dizer que cé finito, a declaração $c=3 \times 108 \mathrm{~m} / \mathrm{s}$ não tem mais conteúdo do que dizer como podemos fazer a conversão de construção humana (o metro) para outra (o segundo). Perguntar sobre como c tem variado ao longo da história cósmica é como perguntar como o número de litros variou para um determinado galão.

Apesar dessa e de outras acusações, o trabalho sobre cosmologia VSL continua.

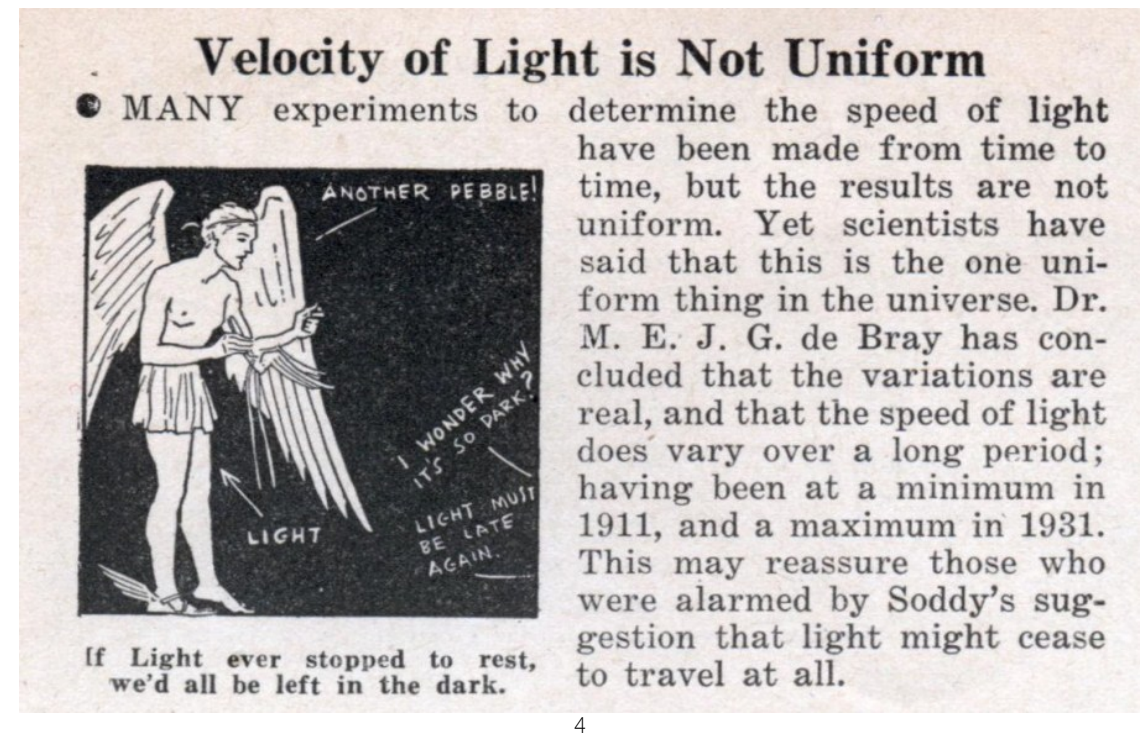

\section{Constantes da natureza}

A velocidade da luz é uma constante fundamental da natureza no sentido de que ela não pode ser reduzida à outras quantidades, tal como se pode fazer com algumas constantes fundamentais. Por exemplo, a aceleração da gravidade na superfície da Terra, $g$ $=9,8 \mathrm{~m} / \mathrm{s}^{2}$, expressa pela constante $\mathrm{G}$ e os valores de Newton para a massa $\mathrm{M}$ e raio $\mathrm{R}$ da Terra: $g=G M / R^{2}$. Há apenas um punhado de constantes verdadeiramente fundamentais (Uzan \& Lehoucq 2005; Kragh 2011, pp. 168-175). Além de c, as mais importantes constantes são:

\footnotetext{
${ }^{4}$ Velocidade da luz não é uniforme | Muitas experiências para determinar a velocidade da luz têm sido feitas ao longo do tempo, mas os resultados não são uniformes. Apesar de que muitos cientistas afirmarem que ela é a única coisa uniforme no universo. Dr. M.E.J.G de Bray concluiu que as variações são reais, e que a velocidade da luz vem variando periodicamente: tendo atingido um mínimo em 1911 e um máximo em 1931. Isso, de certa forma, serve para tranquilizar aqueles que estavam alarmados pela sugestão de Soddy que a luz poderia absolutamente para de viajar. Legenda: Se a luz parar para descansar, todos nós ficaremos no escuro. (nota do tradutor)
} 
Massa do elétron

Massa do próton

Carga elementar

Constante gravitacional

Constante de Planck

$$
\begin{aligned}
& m=(9.10938215 \pm 0.00000045) \times 10^{-31} \mathrm{~kg} \\
& M=(1.672621777 \pm 0.000000074) \times 10^{-31} \mathrm{~kg} \\
& e=(1.602176487 \pm 0.000000040) \times 10^{-19} \mathrm{C} \\
& G=(6.67428 \pm 0.00067) \times 10^{-11} \mathrm{~m}^{3} / \mathrm{kg} / \mathrm{s}^{2} \\
& h=(6.62606896 \pm 0.00000033) \times 10^{-34} \mathrm{~J} . \mathrm{s}
\end{aligned}
$$

Os valores numéricos e suas incertezas padrão são dados pelo National Institute of Standards and Technology [NIST]. As constantes são determinadas empiricamente e, consequentemente, seus valores incluem incertezas experimentais. A este respeito, c destaca-se como uma notável exceção. A diferença pode ser ilustrada por uma experiência de pensamento na qual os valores das constantes são subitamente reduzidos por um fator de, digamos, um milhão. Podemos por decreto mudar $c=3 \times 108 \mathrm{~m} / \mathrm{s}$ para $c=300 \mathrm{~m} / \mathrm{s}$, sem que a mudança tenham quaisquer efeitos observáveis. Nós simplesmente não notarem a mudança. Se, por outro lado, a carga elementar subitamente fosse alterada de $e=1,6 \times$ $10^{-19} \mathrm{C}$ para $e=1.6 \times 10^{-25} \mathrm{C}$ (e outras constantes permanecem as mesmas), haveria consequências mais drásticas, incluindo a imediata destruição de toda a vida no universo.

Embora os valores das constantes da natureza não sejam convencionais em si, seus valores numéricos obviamente o são. Estes valores são expressos em um sistema de unidades que se convencionou escolher e reflete as circunstâncias sociais e culturais no momento da adoção do sistema. Uma civilização avançada em algum planeta distante, presumivelmente, reconheceria o significado das mesmas constantes da natureza, mas que não iria dispor dos mesmos valores numéricos para elas, uma vez que iria adotar um sistema de unidades adaptado às circunstâncias particulares dessa civilização. No entanto, as coisas são diferentes se fala na classe de constantes adimensionais, ou seja, combinações de constantes da natureza que são números puros - sem dimensões e sem unidades. Exemplos importantes desta classe são

$$
\frac{M}{m} \cong 1836 \frac{2 \pi i e^{2}}{h c} \cong 0,0073 \quad \frac{2 \pi G M}{h c} \cong 5 \times 10^{-39}
$$

A segunda das quantidades é a chamada constante de estrutura-fina, próxima a 1/137, e a terceira quantidade é conhecida como a constante de acoplamento gravitacional.

Os valores de constantes desse tipo são os mesmos, independentemente do sistema de unidades adotado, portanto, uma civilização distante chegaria aos mesmos números que nós chegamos. Em outras palavras, eles são não antropomórficas. Os cientistas podem concordar com muitas convenções, decidir como as coisas são, mas independentemente do que acordarem não poderão alterar a relação $\mathrm{M} / \mathrm{m}$ entre as massas de um próton e um elétron. Também não podem convencionalmente decidir que 24 litros de um gás em condições normais de pressão e temperatura deve conter, digamos, 8,31 × $10^{15}$ moléculas. Nessas condições $22,4 \mathrm{~L}$ de qualquer gás contém $6,02 \times 10^{23}$ moléculas (o número de Avogadro). Um número escolhido pela natureza e que não podemos mudar, por mais que quiséssemos.

\section{Tempo convencional}

O parâmetro de tempo utilizado nas leis da dinâmica e muitos outros contextos científicos ilustra, de várias maneiras, os aspectos convencionais de um conceito físico fundamental. Os cientistas utilizam essencialmente, o mesmo conceito de tempo que é usado na vida diária, mas há casos em que a medida de tempo comum t é pouco 
adequada. Por esta razão, por vezes, os cientistas têm sugerido fazer uso de uma nova medida de tempo, por exemplo, introduzindo medida $\ominus$ que se relaciona logaritmicamente com o tempo vulgar:

$$
\theta=k \cdot \log \cdot t+\theta_{0}
$$

Se essa medida de tempo for escolhida, irá levar a uma nova descrição de fenômenos naturais. Este jogo, substituir t-tempo com algum outro $\ominus$-tempo, a muito tem sido jogado na arena cosmológica. Em primeiro lugar, na tentativa de explicar o universo em expansão e ainda manter os redshifts ${ }^{5}$ de galáxias observados e lei de Hubble. De acordo com o ponto de vista convencionalista do cosmólogo britânico E. Arthur Milne, que introduziu a ideia na década de 1930, não é significativo perguntar se o universo está se expandindo realmente ou não. As duas escalas de tempo resultam em duas diferentes imagens físicas de uma mesma realidade. A escolha de qual usar é uma questão de conveniência. Seguindo Milne, em um pequeno artigo de 1940, Karl Popper argumentou que a discussão sobre o universo em expansão versus universo estático não tinha substância empírica real, era uma discussão sobre convenções. Popper ilustrou seu ponto de vista por meio da seguinte analogia (Popper 1940):

As [duas] teorias são logicamente equivalentes e, portanto, não descrevam fatos diferentes, mas os mesmos fatos em idiomas alternativos. Perguntar se "na realidade" o universo se expande, c diminui ou as freqüências aceleram, é tão legítimo quanto perguntar se "na realidade" o valor do dinheiro aumentou ou o valor dos bens diminuiu, quando preços de bens caem em determinado sistema econômico.

É importante salientar que Popper não era uma convencionalista. Pelo contrário, ele reconheceu que o maior perigo de convenções, era tornar muito fácil fugir de conflitos entre teoria e experimentos. De acordo com o ponto de vista convencionalista, uma distinção entre teorias falseáveis e não falseáveis seria ambígua ou mesmo impossível, assim, desafiava diretamente o coração da filosofia de Popper. Em sua obra principal, The Logic of Scientific Discovery, Popper disse: "A única maneira de evitar o convencionalismo é tomando uma decisão: a decisão de não aplicar seus métodos. Decidir que, no caso de uma ameaça ao nosso sistema, não devemos protegê-lo com qualquer tipo de estratagema convencionalista" (Popper 1959, p.82).

$\theta$-tempo se estende infinitamente longe do tempo t quando este se aproxima de zero. Ao invés de dizer que o universo foi criado em $t=0$, em $\theta$-tempo diremos que o universo tem existido em uma eternidade de tempo e, portanto, não tem um começo singular. Alguns físicos consideram o $\theta$-tempo mais fundamental em um contexto cosmológico e usam a transformação para questionar a realidade do Big Bang ou para compreendê-lo de uma maneira diferente (Lévy-Leblond 1990). Usando $\theta$-tempo pode-se argumentar que "o universo é infinitamente velho porque muitas coisas significativas aconteceram infinitamente desde o início" (Misner 1969, p. 1331).

Unidades para quantidades físicas são convencionais e, consequentemente, mudam ao longo da História. Este também é o caso para a unidade de tempo, um segundo, está atualmente definido como 9.192.631.770 períodos de uma certa linha espectral do Césio133. Como sabemos que esta radiação é emitida de maneira uniforme, isto é, com

\footnotetext{
${ }^{5}$ deslocamento para o vermelho (nota do tradutor)
} 
frequência constante? A mesma pergunta pode ser feita sobre as formas anteriores de padrão de tempo, na verdade, de qualquer relógio. Como sabemos que um relógio de pêndulo mantém o controle do tempo? Ou o Sol, durante o seu curso sobre o céu? Na prática, muitas vezes, para comparar certos relógios com um melhor, em última análise, usamos o relógio padrão utilizado para definir a unidade de tempo. No entanto, os bons relógios que usamos, nunca poderão evitar a questão da uniformidade de tempo, já que não há maneira de comparar o tempo dos relógios com "o próprio tempo". Somos forçados a escolher um relógio padrão e postular que ele opera sem problemas. Esta é uma convenção básica em todas as medições de tempo.

Convenções científicas são, usualmente, justificadas cuidadosamente e estão longe serem escolhas arbitrárias, mas por sua própria natureza, poderiam ter sido escolhidas de forma diferente. Estritamente falando, a única exigência é que elas sejam internamente consistentes. Como vimos, muitas convenções diferentes são possíveis, mas o preço para tais possibilidades é muitas vezes proibitivamente alto. Assim, a nossa escolha convencional de um relógio padrão - ou, historicamente, toda uma série de relógios padrão - é justificada pelo conhecimento que usamos para medir esse tempo tornando o mundo racionalmente compreensível. Se tivéssemos adotado um relógio padrão muito diferente, isso não seria o caso. Poderíamos, em princípio, apresentar uma medida do tempo $\Psi=\Psi(t)$, onde $\Psi$ varia de alguma forma irregular com $t$, por convenção, $\psi$-tempo agora opera de maneira uniforme e, portanto, $t$-tempo funciona de maneira altamente irregular. Com essa medida de tempo um pêndulo não se moveria periodicamente, nem átomos emitiriam luz em frequências definidas. E as luas de Júpiter se moveriam em direções aleatórias que não revelariam a terceira lei de Kepler. A ciência física seria impossível e entenderíamos praticamente nada do mundo que nos rodeia.

\section{Referências}

Alder, Ken (2004). The Measure of All Things. London: Abacus.

Alonso, Marcelo and Edward J. Finn (1968). Fundamental University Physics, Vol. 1. Reading, Mass.: Addison-Wesley.

Ben-Menahem, Yemima (2006). Conventionalism. Cambridge: Cambridge University Press.

De Bièvre, P. and H. S. Peiser (1992). Atomic weight - the name, its history, definition, and units. Pure \& Applied Chemistry 64, 1535-1543.

Duff, Michael J. (2004). Comment on time-variation of fundamental constants. arXiv:hep-th/0208093.

Ellis, George and Jean-Philippe Uzan (2005). ' $C$ ' is the speed of light, isn't it? American Journal of Physics 73, 240-247.

Flick, L. B. and N. G. Lederman, eds. (2006). Scientific Inquiry and Nature of Science: Implications for Teaching, Learning, and Teacher Education. Dordrecht: Springer.

Hacyan, Shahen (2009). What does it mean to modify or test Newton's second law? American Journal of Physics 77, 607-609.

Hanson, Norwood R. (1965). Patterns of Discovery: An Inquiry into the Conceptual Foundations of Science. Cambridge: Cambridge University Press.

Holden, Norman E. (2004). Atomic weights and the International Committee - a historical review. Chemistry International 26 (online edition).

IAU: http://en.wikipedia.org/wiki/IAU_definition_of_planet. 
Jammer, Max (1962). Concepts of Force: A Study in the Foundations of Dynamics. New York: Harper Torchbooks.

Kauffmann, George B. (1988). The Brønsted-Lowry acid-base concept. Journal of Chemical Education 65, 28-31.

Kragh, Helge (2000). Conceptual changes in chemistry: The notion of a chemical element, ca. 1900 1925. Studies in History and Philosophy of Modern Physics 31, 435-450.

Kragh, Helge (2006). Cosmologies with varying speed of light: A historical perspective. Studies in History and Philosophy of Modern Physics 37, 726-737.

Kragh, Helge (2011). Higher Speculations: Grand Theories and Failed Revolutions in Physics and Cosmology. Oxford: Oxford University Press.

Laidler, Keith J. (1993). The World of Physical Chemistry. Oxford: Oxford University Press.

Layer, Howard P. (2008). Length - Evolution from Measurement Standard to a Fundamental Constant. Gaithersburg, MD: National Institute of Standards and Technology.

Lévy-Leblond, Jean-Marc (1990). Did the big bang begin? American Journal of Physics 58, 156-159.

McComas, William F., ed. (1998). The Nature of Science in Science Education: Rationales and Strategies. Boston: Kluwer Academic.

Misner, Charles W. (1969). Absolute zero of time. Physical Review 186, 1328-1333.

Newton, Roger G. (1997). The Truth of Science: Physical Theories and Reality. Cambridge, Mass.: Harvard University Press.

NIST: http://physics.nist.gov/cuu/Constants/index.html

Paneth, Fritz A. (1962). The epistemological status of the chemical concept of element. British Journal for the Philosophy of Science 13, 1-14, 145-160.

Poincaré, Henri (1952). Science and Hypothesis. New York: Dover Publications.

Popper, Karl R. (1940). Interpretations of nebular red-shifts. Nature 145, 69-70.

Popper, Karl R. (1959). The Logic of Scientific Discovery. New York: Basic Books.

Rosen, Edward, ed. (1959). Three Copernican Treatises. New York: Dover Publications.

Smith, George E. (2006). The vis viva dispute: A controversy at the dawn of dynamics. Physics Today 59 (October), 31-36.

Szabadvary, F. (1964). Development of the pH concept: A historical survey. Journal of Chemical Education 41, 105-107.

Uzan, Jean-Philippe and Bénédicte Lehoucq (2005). Les Constantes Fondamentales. Paris: Belin.

Van Brakel, Jap (2000). Philosophy of Chemistry: Between the Manifest and the Scientific Image. Leuven: Leuven University Press.

Weintraub, David A. (2007). Is Pluto a Planet? A Historical Journey Through the Solar System. Princeton: Princeton University Press.

Wolfenden, J. H. (1972). The anomaly of strong electrolytes. Ambix 19, 175-196. 